\title{
Abnormal interactions between context, memory structure, and mood in schizophrenia: An ERP investigation
}

\author{
ANA P. PINHEIRO, ${ }^{\mathrm{a}, \mathrm{b}}$ ELISABETTA DEL RE, ${ }^{\mathrm{b}, \mathrm{c}}$ PAUL G. NESTOR, ${ }^{\mathrm{c}, \mathrm{d}} \mathrm{JENNA}^{\mathrm{N}}$ MEZIN, ${ }^{\mathrm{b}, \mathrm{c}}$ NEGUINE REZAII, ${ }^{\mathrm{b}, \mathrm{c}}$ \\ ROBERT W. MCCARLEY, ${ }^{\mathrm{b}, \mathrm{c}}$ ÓSCAR F. GONÇALVES, ${ }^{\mathrm{a}}$ AND MARGARET NIZNIKIEWICZ ${ }^{\mathrm{b}, \mathrm{c}}$ \\ ${ }^{a}$ Neuropsychophysiology Laboratory, CIPsi, School of Psychology, University of Minho, Braga, Portugal \\ ${ }^{\mathrm{b}}$ Cognitive Neuroscience Laboratory, Department of Psychiatry, Harvard Medical School, Boston, Massachusetts, USA \\ ${ }^{\mathrm{c}}$ Department of Psychiatry, Boston VA Healthcare System, Brockton, Massachusetts, USA \\ dDepartment of Psychology, University of Massachusetts, Boston, Massachusetts, USA
}

\begin{abstract}
This study used event-related potentials to examine interactions between mood, sentence context, and semantic memory structure in schizophrenia. Seventeen male chronic schizophrenia and 15 healthy control subjects read sentence pairs after positive, negative, or neutral mood induction. Sentences ended with expected words (EW), within-category violations (WCV), or between-category violations (BCV). Across all moods, patients showed sensitivity to context indexed by reduced $\mathrm{N} 400$ to EW relative to both WCV and BCV. However, they did not show sensitivity to the semantic memory structure. N400 abnormalities were particularly enhanced under a negative mood in schizophrenia. These findings suggest abnormal interactions between mood, context processing, and connections within semantic memory in schizophrenia, and a specific role of negative mood in modulating semantic processes in this disease.
\end{abstract}

Descriptors: Schizophrenia, Language, Affect, Semantic memory, N400

Our knowledge of the world stored in semantic memory networks consists of concepts taxonomically organized on the basis of perceptual and functional similarities between items (e.g., Collins \& Loftus, 1975), reflecting structure in the perceived world (e.g., Rosch, 1999).

More recent studies suggest that affect influences the processing of meaning during real-time language comprehension and, in particular, the interactions between semantic memory organization and a sentence context (Federmeier, Kirson, Moreno, \& Kutas, 2001; Pinheiro, Del Re, Nestor et al., 2013). For example, we demonstrated that, under positive mood, the contextually unexpected word "apartment" is processed like an expected word "mansion," while under negative mood both unexpected words "apartment" and "tent" are processed in a similar way, as indexed by N400 amplitude (Pinheiro, Del Re, Nestor et al., 2013). This evidence fits with anecdotal and experimental reports suggesting

This work was supported by a post-doctoral grant (BPD/68967/2010) and FCT Investigator Grant (IF/00334/2012) from Fundação para a Ciência e a Tecnologia (FCT; Portugal) awarded to APP, by a research grant (PTDC/ PSI-PCL/116626/2010) funded by FCT and by European Regional Development Fund awarded to APP, and by two grants from the National Institute of Mental Health (NIMH; RO1 MH 040799 grant awarded to RWM; RO3 MH 078036 grant awarded to MAN). We gratefully acknowledge all the participants of this study for their contribution to science. Many thanks also to Elizabeth Thompson for her help with data acquisition, and to two anonymous reviewers for their insightful and helpful comments on earlier versions of this manuscript.

Address correspondence to: Margaret Niznikiewicz, Ph.D., Department of Psychiatry-116A, Boston VA Healthcare System, 940 Belmont Street, Brockton, MA 02301, USA. E-mail: margaret_niznikiewicz@ hms.harvard.edu or Ana P. Pinheiro, e-mail: ana.pinheiro@psi.uminho.pt that the positive mood broadens the boundaries of semantic taxonomies leading to more flexible and creative thinking but also to more errors, while negative mood narrows such boundaries leading to more rigid thinking but also to fewer errors (e.g., Bolte, Goschke, \& Kuhl, 2003; Dreisbach, 2006; Dreisbach \& Goschke, 2004; Isen, Johnson, Mertz, \& Robinson, 1985; Phillips, Bull, Adams, \& Fraser, 2002; Rowe, Hirsh, \& Anderson, 2007). However, it is not clear how these sources of information interact when affective and semantic processing is abnormal, as in schizophrenia. The investigation of these interactions is particularly important considering that abnormal access to semantic memory may underlie some of the schizophrenia symptoms, such as thought disorder (e.g., Mathalon, Roach, \& Ford, 2010; Nestor et al., 1998).

\section{Language, Semantic Memory, and Mood Interactions in Nonclinical Subjects}

In healthy individuals, recent event-related potential (ERP) studies suggest that the N400, a negative component peaking around 400 ms after a target word onset, can index interactions between context-based prediction processes, the structure of the semantic memory, and mood states (Federmeier \& Kutas, 1999a, 1999b; Federmeier et al., 2001; Pinheiro, Del Re, Nestor et al., 2013). More specifically, these studies demonstrate that N400 can be sensitive to both context and memory structure. The N400 amplitude sensitivity to context is revealed by a differential N400 response to words that make either valid or invalid sentence endings (context effect). N400 amplitude is also sensitive to context-independent feature similarity between concepts in 
semantic memory, which is indexed by a graded N400 response to invalid sentence endings sharing more semantic features with an expected item relative to invalid sentence endings sharing fewer semantic features with an expected item (semantic memory structure effect). Sentence context and the structure of semantic memory have mutually dependent effects on N400 amplitude, which is indexed by a graded N400 pattern with the least negative N400 to expected words, with intermediate N400 to words sharing more semantic features with the expected word, and with the most negative N400 to words sharing fewest semantic features with the expected word. Furthermore, these studies demonstrate, using N400 as an index, how mood may change the interactions between sentence context and access to semantic memory structure.

Our previous ERP study with healthy subjects (Pinheiro, Del Re, Nestor et al., 2013) demonstrated a facilitative effect of positive mood and constraining effect of negative mood on access to long-term semantic memory during sentence comprehension. This study used sentence pairs presented after neutral, positive, and negative mood induction. The final word of the second sentence was an expected word (EW) or one of two types of unexpected words: a within-category violation (WCV), that is, an unexpected word from the same semantic category as the EW; or a betweencategory violation $(\mathrm{BCV})$, that is, an unexpected word from a different semantic category than the EW. For example, in the sentence pair, "Louise was suffering from a toothache for several days, but she still refused to do anything about it. She has always been afraid of going to the ..."- "dentist" is the expected word $(\mathrm{EW})$, "doctor" is a WCV, and "librarian" is a BCV. Despite being exemplars of a different semantic category, BCV shared most general dimensions of the corresponding EW and belonged to the same higher-level category (e.g., jobs) ${ }^{1}$ (Federmeier \& Kutas, 1999a).

Under neutral mood, a predictive role of context was evident in the N400 difference to expected and unexpected words: N400 to both WCV and BCV was more negative than N400 to EW, indicating difficulties in the integration of meaning of unexpected words (e.g., Holcomb, 1993) or more difficulties in accessing unexpected words from semantic memory, when compared with expected endings (e.g., Deacon, Hewitt, Yang, \& Nagata, 2000; Kutas \& Federmeier, 2000). A role of memory structure was evident in the less negative N400 to WCV, which shared more semantic features with the EW, than to BCV, with both word types making nonsensical sentence endings. This result indicated that the structure of semantic memory also affected how words were processed, such that WCV were more easily integrated into their sentence context or were more easily accessed from the word lexicon than BCV even though they formed unexpected endings (e.g., Federmeier \& Kutas, 1999a, 1999b). A role of mood was evident in $\mathrm{N} 400$ differences in the positive and negative mood conditions. Under positive mood, WCV were processed as if they were correct endings (no N400 difference between EW and WCV), while $\mathrm{BCV}$ remained treated as unacceptable endings and were associated with increased $\mathrm{N} 400$ relative to EW and WCV. Under negative mood, both WCV and BCV were processed similarly and

1. Another example would be the superordinate category of human dwellings: "mansion" (EW), "apartment" (WCV), and "tent" (BCV): "The Joneses made so much money that they no longer wanted to live in their small house so they moved to the outskirts of the town to a very fashionable subdivision. There, they bought a huge mansion (EW)/apartment (WCV)/ tent (BCV)." associated with increased N400 relative to EW. No similar ERP study examining the influence of context and its interaction with semantic memory structure and mood has been conducted in schizophrenia.

\section{Language and Memory Structure in Schizophrenia}

Studies on language function in schizophrenia using both behavioral and ERP methodologies suggested abnormal processes within semantic networks and abnormal use of context (e.g., Condray, Siegle, Cohen, van Kammen, \& Steinhauer, 2003; Kiefer, Martens, Weisbrod, Hermle, \& Spitzer, 2009; Kumar \& Debruille, 2004; Mohammad \& DeLisi, 2013; Nestor et al., 1998; Niznikiewicz et al., 1997; Niznikiewicz, Mittal, Nestor, \& McCarley, 2010; Onitsuka, Oribe, Nakamura, \& Kanba, 2013; Salisbury, O’Donnell, McCarley, Nestor, \& Shenton, 2000; Salisbury, Shenton, Nestor, \& McCarley, 2002; Sitnikova, Salisbury, Kuperberg, \& Holcomb, 2002). Most ERP studies on context processing in schizophrenia found increased N400 to both congruent and incongruent sentence endings (Nestor et al., 1997; Niznikiewicz et al., 1997; Salisbury et al., 2000, 2002; Sitnikova et al., 2002), suggestive of difficulties in using semantic context. Studies that specifically looked at the processes within semantic networks found evidence for abnormal connectivity within semantic memory (Nestor et al., 1998, 2001) and abnormal structure of semantic knowledge (Kiang, Kutas, Light, \& Braff, 2007; Mathalon et al., 2010; Paulsen et al., 1996). For example, Nestor et al. (1998) tested recall of words varying in connectivity (i.e., associative strength) and network size (number of associates) and found reduced word recall in schizophrenia patients relative to healthy controls (HC) due to the effects of abnormal connectivity but not to network size. Also, schizophrenia patients did not distinguish between nonexemplars and low-typicality exemplars of a given semantic category (Kiang et al., 2007). Given these results, we predicted a lack of differences between WCV and BCV in the schizophrenia group.

\section{Emotional Processing and Mood Effects in Schizophrenia}

Previous studies on emotional processing in schizophrenia identified abnormalities in the perception of emotional cues from faces (e.g., Gur et al., 2002) and voice (e.g., Leitman et al., 2010; Pinheiro, Del Re, Mezin et al., 2013), as well as in the expression of emotion (e.g., Kring \& Neale, 1996), which do not seem to be consistently related to a specific valence type (e.g., positive or negative). However, in-the-moment emotional experience (e.g., Herbener, Rosen, Khine, \& Sweeney, 2007; Herbener, Song, Khine, \& Sweeney, 2008) and the representation of affective knowledge (Kring, Barrett, \& Gard, 2003; Pinheiro, Liu et al., 2013) seem to be better preserved. Other studies investigating self-reported emotional experience after mood induction procedures demonstrated increased levels of negative mood after both positive and negative mood induction in schizophrenia relative to HC (e.g., Earnst \& Kring, 1999; Kring \& Neale, 1996; Pinheiro, Liu et al., 2013). Additionally, the observation that schizophrenia individuals show higher emotional reactivity to daily life stress (Myin-Germeys, Nicolson, \& Delespaul, 2001) and that affective changes elicited by aversive events may be related to positive symptomatology (Myin-Germeys \& van Os, 2007) suggests a role that increased negative mood in schizophrenia may play in abnormal cognitive processing. 


\section{Interaction Between Language, Memory Structure, and Mood in Schizophrenia}

The few studies that examined the interactions between affect and cognition in schizophrenia reported abnormal interactions between negative affect and cognitive processing (Docherty \& Hebert, 1997; Habel et al., 2010; Pauly et al., 2008). Relative to HC, schizophrenia patients were characterized by hypoactivation of the medial orbitofrontal and middle frontal areas in an $n$-back working memory task during negative mood induction via odorants (Habel et al., 2010); worse performance in a verbal $n$-back task during negative olfactory mood induction (Pauly et al., 2008); and stronger disorganization of speech after induction of laboratory stress (Docherty \& Hebert, 1997).

Given these findings, we predicted abnormal processing of a sentence context and access to semantic memory structure as a function of mood in schizophrenia. In particular, we hypothesized that (a) abnormalities in sentence context processing would be indexed by a smaller difference in N400 amplitude between expected and unexpected endings in schizophrenia patients relative to $\mathrm{HC}$, and (b) semantic structure and function abnormalities would be reflected in the lack of differences between WCV and BCV.

We additionally predicted (c) a stronger influence of negative mood on sentence comprehension and reduced reactivity to positive evocative pictures. This would be indexed by reduced differences between the three types of sentence endings under negative mood, relative to both neutral and positive mood conditions.

Besides the analysis of N400 data, we have explored selfreports of mood before and after mood induction, as well as ratings of valence (i.e., the overall unpleasantness/displeasure relative to the pleasantness/attraction of a stimulus, ranging from $1=$ unpleasant to $9=$ pleasant) and arousal (i.e., the intensity of motivational mobilization elicited by a stimulus, ranging from $1=\mathrm{calm}$ to $9=$ aroused ) of the affective pictures selected for mood induction purposes. We expected mood changes after the presentation of evocative pictures in both groups with a different pattern of changes in patients and HC. In comparison with HC, we hypothesized that patients would report higher levels of negative mood after both positive and negative mood induction sessions (consistent with Earnst \& Kring, 1999; Kring \& Neale, 1996; Pinheiro, Liu et al., 2013). Additionally, considering evidence supporting intact representations of affective knowledge in patients (e.g., Horan, Wynn, Kring, Simons, \& Green, 2010; Pinheiro, Liu et al., 2013), we expected no group differences in ratings of valence and arousal of affective pictures.

\section{Method}

\section{Participants}

Seventeen male chronic schizophrenia patients and 15 male HC participated in the study (see Table 1). The HC participants were the same as in Pinheiro, Del Re, Nestor et al. (2013). Inclusion criteria for participation in this study were age between 18 and 50 years; right handedness (Oldfield, 1971); no current mood episodes; no history of neurological illness; no history of alcohol or drug dependence in the past 5 years or abuse within the last year (APA, 2000); no current medication for medical disorders that would have effects on electroencephalogram (EEG) morphology or consequences at the level of neurological and/or cognitive functioning; verbal intelligence quotient (IQ) above 85 (Wechsler, 1997); no alcohol use in the $24 \mathrm{~h}$ before testing; no hearing, vision, or upper body impairment; an ability and desire to cooperate with the experimental procedures, as demonstrated by given written informed consent. For HC, an additional exclusion criterion was a history of psychiatric disorder in oneself or in first-degree relatives.

Patients were recruited through Internet advertisements, from outpatient clinics affiliated with Harvard Medical School, or through referrals from clinicians. They were stabilized outpatients, with no current mood episodes. Patients' diagnoses were based on interviews with the Structured Clinical Interview for DSM-IV for

Table 1. Demographic, Cognitive, and Clinical Characterization of Participants

\begin{tabular}{|c|c|c|c|}
\hline & $\begin{array}{c}\mathrm{HC} \\
M(S D)\end{array}$ & $\begin{array}{c}\text { Schizophrenia group } \\
M(S D)\end{array}$ & $\begin{array}{l}\text { Significance test } \\
\qquad F, p\end{array}$ \\
\hline Age & $45.06(8.93)$ & $48.31(8.77)$ & $1.08,0.31$ \\
\hline Years of education & $14.72(1.73)$ & $13.94(1.91)$ & $1.47,0.24$ \\
\hline Parents' socioeconomic status & $2.19(1.05)$ & $2.82(1.24)$ & $2.53,0.12$ \\
\hline Subject's socioeconomic status & 2.06 (1.12); range $1-4$ & 3.00 (1.17); range1-5 & $5.49,0.026 *$ \\
\hline Verbal IQ ${ }^{\mathrm{a}}$ & $106.53(18.60)$ & $98.84(10.54)$ & $1.68,0.21$ \\
\hline Full-scale IQ ${ }^{\mathrm{a}}$ & $106.72(16.97)$ & $96.61(7.44)$ & $3.78,0.07$ \\
\hline Vocabulary $^{\mathrm{a}, \mathrm{b}}$ & $11.08(3.09)$ & $10.23(2.68)$ & $0.55,0.47$ \\
\hline Working memory index ${ }^{a}$ & $97.50(34.09)$ & $93.31(8.72)$ & $0.18 ; 0.67$ \\
\hline Chlorpromazine equivalent (mg) & n.a. & $521.10(470.30)$ & n.a. \\
\hline Illness duration & n.a. & $14.13(9.47)$ & n.a. \\
\hline Age of onset & n.a. & $27.71(8.62)$ & n.a. \\
\hline Antipsychotic medication type & n.a. & $\begin{array}{l}\text { Typical (fluphenazine decanoate, proloxin decanoate, } \\
\text { haloperidol) }=1 \text {; Atypical (risperidone, olanzapine, } \\
\text { ziprasidone, quetiapine, aripiprazole) }=11 \text {; Both }=2\end{array}$ & n.a. \\
\hline Positive PANSS & n.a. & $22.29(8.79)$ & n.a. \\
\hline Negative PANSS & n.a. & $20.24(9.53)$ & n.a. \\
\hline General PANSS & n.a. & $40.12(16.62)$ & n.a. \\
\hline Total PANSS & n.a. & $82.65(30.96)$ & n.a. \\
\hline Global SAPS & n.a. & $10.18(3.09)$ & n.a. \\
\hline Global SANS & n.a. & $10.44(6.43)$ & n.a. \\
\hline
\end{tabular}

Note. $\mathrm{HC}=$ healthy controls; $n . a$. = nonapplicable.

${ }^{\mathrm{a}}$ WAIS-III: Wechsler Adult Intelligence Scale-III (Wechsler, 1997); ${ }^{\mathrm{b}}$ scaled score.

*statistically significant. 
Table 2. Ratings of IAPS Visual Stimuli in Healthy Controls and Schizophrenia Patients

\begin{tabular}{|c|c|c|c|c|}
\hline & Condition & $\begin{array}{l}\text { IAPS normative } \\
\text { sample } \\
(\text { mean } \pm S D)\end{array}$ & $\begin{array}{c}\text { Healthy control } \\
\text { subjects } \\
\text { (mean } \pm S D)\end{array}$ & $\begin{array}{c}\text { Schizophrenia } \\
\text { patients } \\
(\text { mean } \pm S D)\end{array}$ \\
\hline Valence & Neutral & $5.05(0.19)$ & $5.08(0.72)$ & $5.04(1.11)$ \\
\hline \multirow[t]{2}{*}{ (ratings from 1 totally unpleasant to 9 totally pleasant) } & Positive & $7.85(0.25)$ & $7.28(1.09)$ & $7.28(0.70)$ \\
\hline & Negative & $2.74(0.35)$ & $2.49(0.77)$ & $2.80(0.73)$ \\
\hline Arousal & Neutral & $2.65(0.36)$ & $2.78(1.59)$ & $3.63(1.38)$ \\
\hline \multirow[t]{2}{*}{ (ratings from 1 totally calm to 9 totally aroused) } & Positive & $4.48(0.38)$ & $5.12(2.57)$ & $5.53(1.91)$ \\
\hline & Negative & $4.78(0.28)$ & $4.70(2.60)$ & $6.26(1.72)$ \\
\hline
\end{tabular}

Axis I (SCID-I; First, Spitzer, Gibbon, \& Williams, 2002) and Axis II (SCID-II; First, Spitzer, Gibbon, \& Williams, 1995) disorders by a clinician, as well as on medical records. Clinical measures included the Positive and Negative Syndrome Scale (PANNS; Kay, Fiszbein, \& Opler, 1987), the Scale for the Assessment of Positive Symptoms (SAPS; Andreasen, 1984) and the Scale for the Assessment of Negative Symptoms (SANS; Andreasen, 1983).

$\mathrm{HC}$ were matched to the patients on age, gender, and handedness, and recruited through Internet advertisements. Groups were also matched on parental socioeconomic status (SES) believed to reflect better educational and socioeconomic opportunities that existed for schizophrenia subjects in their home of origin but were not realized as a consequence of the disease, adopting the approach used in most studies on schizophrenia. They were screened using the SCID-I (First et al., 2002) and SCID-II (First et al., 1995) interviews.

The HC data have been presented in Pinheiro, Del Re, Nestor et al. (2013). They are discussed here to the extent that they provide a comparison for the pattern of results observed in the schizophrenia group. Additionally, they are presented in the group analyses, which follow traditional designs where no mood is manipulated: the N400 data are compared between the HC and schizophrenia participants. The HC and schizophrenia data have been collected in close temporal proximity and following identical experimental protocols.

\section{Materials}

Stimuli included 324 pairs of sentences, distributed across three main lists. The sentence pairs ended with three possible types of target words: EW, WCV, or BCV. Considered separately, the second sentence was completed appropriately by each of the critical word types. Additionally, for mood induction purposes, 30 pictures with positive (e.g., babies, people smiling), 30 with negative (e.g., people crying, mutilation), and 30 with neutral valence (e.g., household objects, vegetables), with moderate levels of arousal were selected from the IAPS database (Lang, Bradley, \& Cuthbert, 2008; see Table 2). Pictures were not semantically related to sentence contexts and sentence endings. ${ }^{2}$

2. IAPS pictures were: negative-2141, 2276, 2278, 2375, 2455, 2700, 2750, 2799, 2900, 3181, 3300, 6311, 6561, 9000, 9007, 9041, 9102, 9180 9265, 9290, 9320, 9419, 9421, 9432, 9435, 9452, 9471, 9561, 9584, 9830; positive-1440, 1441, 1460, 1610, 1750, 1811, 1920, 2040, 2050, 2057, $2070,2080,2150,2154,2160,2165,2170,2260,2311,2332,2340,2530$, 2540, 2550, 2660, 5600, 5780, 5830, 5831, 7580; neutral-2038, 2880, $5130,5510,5520,5530,6150,7000,7002,7004,7006,7010,7020,7034$ 7035, 7041, 7050, 7053, 7055, 7056, 7059, 7080, 7090, 7179, 7187, 7217, $7233,7235,7490,7950$
Details on sentences' development and procedures are provided in Pinheiro, Del Re, Nestor et al. (2013). Stimuli development followed Federmeier and Kutas (1999a, 1999b). The expected words were selected based on a separate study where cloze probabilities for the final words of each of the 324 sentence contexts were calculated $\left(n=26 ; M_{\text {age }}=24.31, S D=6.93\right.$, age range: $21-57$ years; 21 females and 5 males). Mean cloze probability for the expected words was 0.75 . The plausibility of all sentence endings within their contexts was also assessed by a different group of 20 individuals $\left(M_{\text {age }}=26.20, S D=12.17\right.$, age range: $17-61$ years; 16 females and 4 males), who were asked to rate how well the sentences made sense together, on a percent scale. Mean rated plausibility for EW was $86.44 \%$, for WCV was $24.22 \%$, and for BCV was $12.54 \%$.

Sentences were divided into three lists of 108 sentences each, corresponding to three experimental blocks. The target word was always the final word of the second sentence. Each target word appeared three times, once in each type of ending-EW, WCV, or $\mathrm{BCV}$, and once per set. The three target word types were matched for length $\left(M_{\text {number of letters }}=5.76 ; S D=1.73\right)$, frequency $(M=50.21$; $S D=79.37)$, imageability $(M=585.93 ; S D=39.67)$, concreteness $(M=582.63 ; S D=44.09)$, and age of acquisition $(M=282.55$; $S D=81.86$ ), taken from the MRC Psycholinguistic Databasehttp://websites.psychology.uwa.edu.au/school/MRCDatabase/uwa _mrc.htm (Coltheart, 1981; Wilson, 1998). All words were short and had high imageability, ${ }^{3}$ concreteness, ${ }^{4}$ and frequency ${ }^{5}$ values, as well as moderate age of acquisition ${ }^{6}$ values.

Each participant viewed a different list in each mood. No sentence context or critical word was repeated within a given list. Each list consisted of 36 targets of each type (see Figure 1). To balance the number of plausible and implausible sentences read by each participant, 36 plausible filler sentences were added to each list. All lists included the same number (72) of expected and unexpected sentence endings.

\section{Procedure}

Participants were tested in three experimental sessions (one session for each mood induction), conducted in a soundproof chamber (see Figure 1). They were seated in a comfortable chair 40 inches in front of a monitor.

3. Imageability values range from 100 to 700 (minimum $=129$; maximum $=669 ; M=450 ; S D=108$ ).

4. Concreteness values range from 100 to 700 ( $\operatorname{minimum}=158$, maximum $=670, M=438, S D=120$ ).

5. Frequency values are based on Brown (1984). Values range from 0 to 6,833 . The mean value is $35(S D=252)$.

6. Age of acquisition values range from 100 to 700 ( $\operatorname{minimum}=125$; maximum $=697 ; M=405 ; S D=120$ ). 


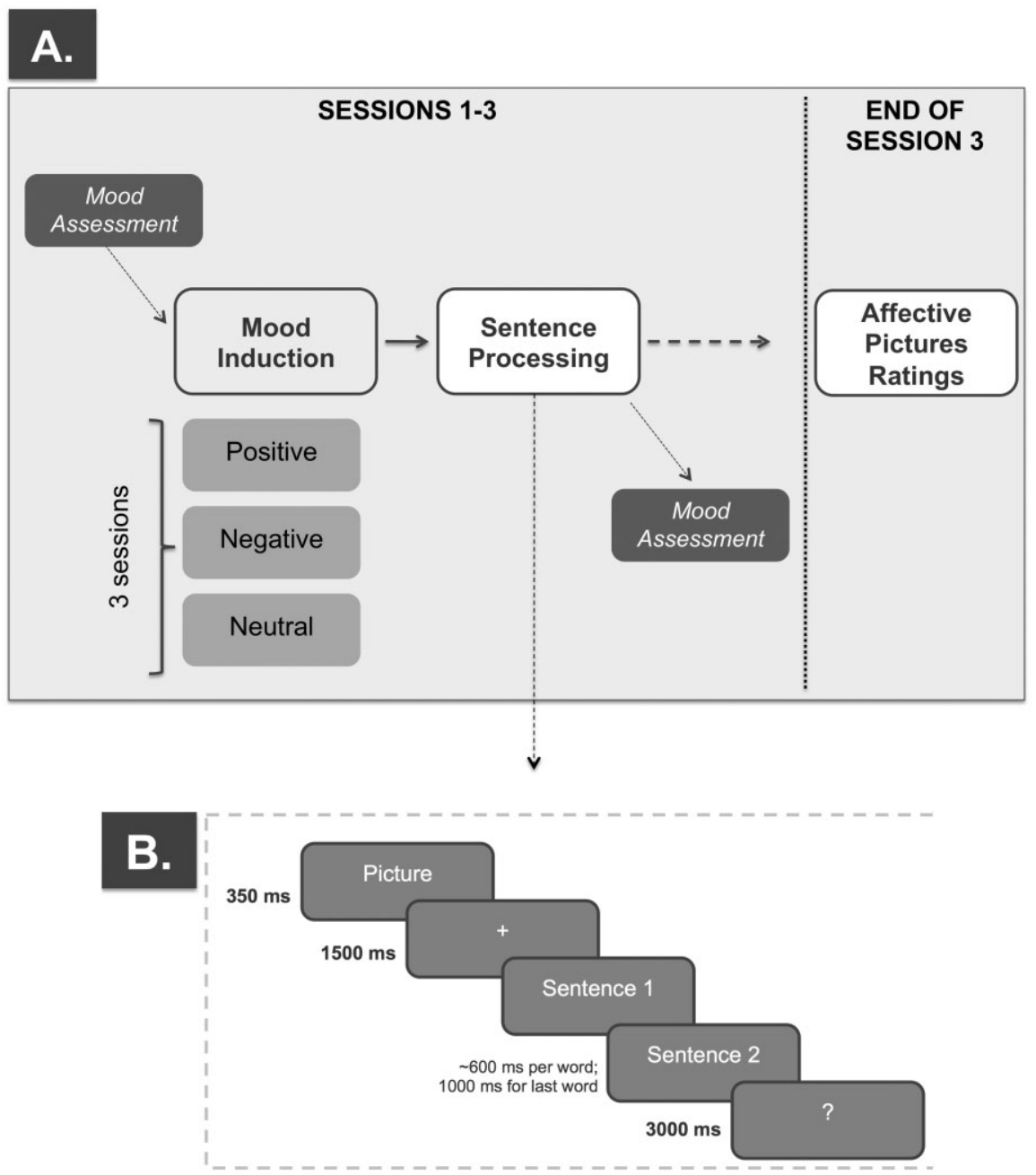

Figure 1. A: Schematic illustration of the experimental design. B: Schematic illustration of an experimental trial.

Mood was assessed before and after mood induction using the Profile of Mood States instrument (POMS; McNair, Lorr, \& Droppleman, 1971), which includes 65 adjectives rated on a 5 -point scale (from $0=$ not at all to $4=$ extremely) and covers different mood states indexed by seven subscales: anger-hostility, depression-dejection, fatigue-inertia, tension-anxiety, confusionbewilderment, vigor-activity, friendliness. This checklist has been used by several studies aiming at investigating mood effects in healthy controls (e.g., Canli, Amin, Haas, Omura, \& Constable, 2004; Demirtas-Tatlidede, Freitas, Pascual-Leone, \& Schmahmann, 2011) and schizophrenia patients (Storms, Clopton, \& Wright, 1982; Wulff, Dijk, Foster, \& Joyce, 2012).

Order of mood induction was counterbalanced across subjects. Sessions were separated by at least a week. Details of the experimental procedure are presented in Figure 1.

Before presentation of sentences, participants saw 30 pictures from the IAPS database (positive, negative, or neutral). Each picture was presented for $1,000 \mathrm{~ms}$ with an interstimulus interval of $2,000 \mathrm{~ms}$. A fixation cross appearing in the center of the screen for 2,000 ms preceded each picture. The order of mood induction was counterbalanced across participants. They were not informed about the true purpose of viewing the pictures but, as in the Federmeier et al. study (2001), they were instructed to pay attention to the stimuli and told that later they would be asked to judge if the pictures were appropriate for use in another experiment (ERP findings are presented in Pinheiro, Liu et al., 2013).

A short practice block consisting of 10 trials representing the three types of sentence conditions preceded the experimental block. Before each pair of sentences, a picture from the set of selected IAPS pictures for a specific mood induction was presented for $350 \mathrm{~ms}$, in order to keep mood constant across the experiment. It was followed by a fixation cross, presented for 1,500 ms. The first sentence of the pair appeared fully on the screen. Participants read each sentence at their own pace and pushed a button to view the second sentence. The second sentence was presented one word at a time, horizontally, each word for about $600 \mathrm{~ms}$. Final words were presented in the center of the screen, for 1,000 ms. Participants were asked not to blink or move their eyes during the second sentence, to minimize EEG artifacts. The final word was followed by a question mark (for 3,000 ms), prompting the participants to make a button press response, after which the next sentence appeared automatically. Subjects were asked to decide if the two sentences together made sense or not. The order of "yes" and "no" response buttons was counterbalanced across subjects. A short break was given after every 20 pairs of sentences. 
At the end of each session, participants also answered a short, written questionnaire consisting of two questions asking (1) how much they liked the pictures, and (2) how much the pictures influenced their decision whether the sentences made sense or not, using a 5-point Likert scale (ranging from $1=$ very slightly or not at all to 5 =extremely for question 1 , and from $1=$ very easy to $5=$ extremely difficult for question 2). At the end of the three sessions, they were also asked to rate the valence and arousal of each picture presented during the emotional elicitation task, using a computerized version of the Self-Assessment Manikin (SAM; Bradley \& Lang, 1994).

\section{EEG Data Acquisition and Analysis}

EEG was collected using custom-designed 64-channel caps (BioSemi, Active 2) in a continuous mode at a digitization rate of $512 \mathrm{~Hz}$ and stored on hard disk for later analysis. Blinks and eye movements were monitored via electrodes placed on left and right temples and one above the left eye.

Raw EEG data were analyzed with Analyzer 1 software package (Brain Products, Inc.). Data were rereferenced offline to the average of the left and right mastoids. Individual ERP epochs were constructed starting $150 \mathrm{~ms}$ before stimulus onset and ending 1,000 $\mathrm{ms}$ after the stimulus onset. Eye blink and movement artifacts were corrected by the method of Gratton, Coles, \& Donchin (1983). Single-trial epochs with voltage exceeding $\pm 100 \mu \mathrm{V}$ were rejected offline from further analysis, before averaging (only data including at least $85 \%$ of trials per condition were kept for further analyses). Separate averages were calculated for each type of target word, after subtraction of the 150-ms prestimulus baseline. Groups did not differ in number of segments included in individual averages $(p>.05)$. N400 was measured as mean amplitude between the latency of 300-500 ms poststimulus onset to each sentence ending type, in each mood, at central $(\mathrm{Cz}, \mathrm{C} 3 / 4)$ and parietal $(\mathrm{Pz}, \mathrm{P} 3 / 4)$ regions.

\section{Statistical Analyses}

All statistical analyses were performed with IBM SPSS 20 software package (SPSS Inc., Chicago, IL). Only significant results are presented $(p<.05)$. Analyses were corrected for nonsphericity using the Greenhouse-Geisser method (the original $d f$ is reported). All significance levels are two-tailed with the preset significance alpha level of $p<.05$. Main effects were followed with pairwise comparisons between conditions, using the Bonferroni adjustment for multiple comparisons.

Behavioral analyses. For the analysis of self-reported mood before and after mood induction, we ran a repeated measures analysis of variance (ANOVA) with mood (neutral, positive, negative), time (pre- and post-), and POMS subscale (vigor-activity, friendliness, tension-anxiety, depression-dejection) as within-subjects factors, and group as between-subjects factor. We focused our analysis on these subscales to reduce statistical complexity that could obscure important effects, and because we believed they could better reflect changes in mood resulting from the visualization of evocative IAPS pictures. The vigor-activity subscale ${ }^{7}$ indicates the extent to which the subject experiences positive feelings such as

7. The vigor-activity subscale is composed of the items "active," "energetic," "full of pep," "lively," "vigorous," and "cheerful." vigor and energy, while the friendliness subscale ${ }^{8}$ reflects the extent to which a subject experiences positive feelings toward others. Since they assess positive mood states, we thought they could better index changes in the emotional experience after positive mood induction. The tension-anxiety subscale ${ }^{9}$ indicates the extent to which the subject experiences increased anxiety, while the depressiondejection subscale ${ }^{10}$ provides information on experienced depression and feelings of personal inadequacy. Since they assess negative mood states, we believed they could better represent changes in the emotional experience after negative mood induction.

Participants' responses to the short postexperiment questionnaire in each mood condition were subjected to a repeated measures ANOVA with mood (3 levels) and question (2 levels) as within-subjects factors, and group as between-subjects factor.

Group differences in valence and arousal ratings of IAPS pictures were tested using independent samples $t$ tests.

Accuracy in sentence judgment was analyzed using a repeated measures ANOVA with mood (3 levels), and sentence condition (3 levels) as within-subjects factors, and group as between-subjects factor.

ERP analyses. Repeated measures ANOVAs were computed for the group comparisons of N400 mean amplitude, with mood (3 levels), sentence condition (3 levels), and region (2 levels: central $-\mathrm{Cz}, \mathrm{C} 3 / 4$; parietal- $\mathrm{Pz}, \mathrm{P} 3 / 4)$ as within-subjects factors, and group as between-subjects factor.

Correlational analyses. To investigate potential effects of medication, chronicity, clinical symptoms, and mood on N400 amplitude, Pearson correlations were computed to test the relationship between N400 amplitude at $\mathrm{Cz}$ and $\mathrm{Pz}$ for all sentence conditions in the three moods and (a) chlorpromazine equivalent, (b) illness duration, (c) symptoms (PANSS, SAPS, and SANS), and (d) selfreport data after mood induction.

\section{Results}

\section{Self-Reported Mood Changes}

A significant effect of time of assessment, $F(1,30)=10.36$, $p=.003$, confirmed differences in self-reported mood resulting from mood induction (see Table 3. A significant Group $\times$ Mood $\times$ Subscale interaction, $F(6,180)=2.21, p=.044$, indicated group differences in self-reported mood that were observed for specific POMS subscales and independent of time of assessment: reduced vigor-activity in patients relative to $\mathrm{HC}$ (neutral mood: $p=.041$; positive and negative mood: $p=.001$ ); reduced friendliness in patients relative to $\mathrm{HC}$ (positive mood: $p=.003$; negative mood: $p=.001$ ); and increased depressiondejection in patients relative to $\mathrm{HC}$ (neutral mood: $p=.025$; positive mood: $p=.016$; negative mood: $p=.030$ ). No group differences were observed for the tension-anxiety scale.

Group differences were additionally observed in the subjective experience of viewing the pictures. A Group $\times$ Mood interaction,

8. The friendliness subscale is composed by the items "sympathetic," "trusting," "considerate," "good natured," "helpful," and "friendly."

9. The tension-anxiety subscale is composed of the items "tense," "panicky," and "carefree."

10. The subscale depression-dejection is composed of the items "sorry for things done," "unworthy," "guilty," "worthless," "desperate," "hopeless," "helpless," "lonely," "terrified," "discouraged," "miserable," "gloom," "blue," and "confused." 
Table 3. Self-Reported Mood Changes by Healthy Controls and Schizophrenia Patients

\begin{tabular}{|c|c|c|c|c|c|c|c|}
\hline \multirow[b]{3}{*}{ Scale } & \multirow[b]{3}{*}{ Moment } & \multicolumn{6}{|c|}{ Mood } \\
\hline & & \multicolumn{2}{|c|}{ Neutral } & \multicolumn{2}{|c|}{ Positive } & \multicolumn{2}{|c|}{ Negative } \\
\hline & & $\mathrm{HC}$ & $\mathrm{SZ}$ & $\mathrm{HC}$ & SZ & $\mathrm{HC}$ & SZ \\
\hline \multirow{2}{*}{ Vigor-activity } & $\mathrm{T} 1$ & $3.38(0.83)$ & $2.83(0.75)$ & $3.57(0.64)$ & $2.65(0.81)$ & $3.62(0.57)$ & $2.63(0.73)$ \\
\hline & $\mathrm{T} 2$ & $3.20(0.61)$ & $2.69(0.81)$ & $3.42(0.52)$ & $2.59(0.77)$ & $3.26(0.82)$ & $2.45(0.91)$ \\
\hline \multirow[t]{2}{*}{ Friendliness } & $\mathrm{T} 1$ & $3.41(0.72)$ & $3.41(0.72)$ & $3.90(0.50)$ & $3.33(0.74)$ & $4.08(0.45)$ & $3.32(0.61)$ \\
\hline & $\mathrm{T} 2$ & $3.74(0.59)$ & $3.32(0.83)$ & $3.97(0.51)$ & $3.11(0.79)$ & $3.88(0.63)$ & $3.02(0.87)$ \\
\hline \multirow[t]{2}{*}{ Tension-anxiety } & $\mathrm{T} 1$ & $1.73(0.44)$ & $1.96(0.62)$ & $1.89(0.39)$ & $1.73(0.51)$ & $1.91(0.51)$ & $1.92(0.80)$ \\
\hline & $\mathrm{T} 2$ & $1.67(0.45)$ & $1.80(0.54)$ & $1.82(0.38)$ & $1.81(0.47)$ & $1.80(0.41)$ & $1.83(0.53)$ \\
\hline \multirow{2}{*}{ Depression-dejection } & $\mathrm{T} 1$ & $1.16(0.26)$ & $1.54(0.54)$ & $1.18(0.22)$ & $1.57(0.65)$ & $1.13(0.22)$ & $1.63(0.88)$ \\
\hline & $\mathrm{T} 2$ & $1.14(0.19)$ & $1.35(0.40)$ & $1.09(0.15)$ & $1.40(0.39)$ & $1.20(0.34)$ & $1.62(0.67)$ \\
\hline
\end{tabular}

Note. Results are based on the Profile of Mood States (POMS) after neutral, positive, and negative mood induction. HC = healthy controls; SZ = schizophrenia patients; T1 = Time 1; T2 = Time 2.

$F(2,60)=6.14, p=.004$, indicated that patients liked less the pictures presented in the negative mood condition only and that seeing these pictures made their decision about the sentences more difficult than $\mathrm{HC}(p=.022)$.

\section{Assessment of Affective Properties of Stimuli}

Independent samples $t$ tests indicated similar ratings of affective pictures by schizophrenia patients and $\mathrm{HC}$ in terms of their valence and arousal $(p>.05)$ (see Table 2).

\section{Accuracy of Sentence Judgment}

A significant effect of sentence condition was observed, $F(2,29)=101.42, p<.001$. Pairwise comparisons revealed more correct responses for EW relative to both WCV $(p<.001)$ and $\mathrm{BCV}$ $(p<.001)$, and more correct responses for $\mathrm{BCV}$ relative to $\mathrm{WCV}$ $(p<.001)$, for all moods and both groups. Groups did not differ in accuracy rates $(p>.05)$ (see Figure 2$)$.

\section{N400 Amplitude}

Confirming group differences in semantic processing under different mood conditions, the ANOVA yielded a significant
Group $\times$ Mood $\times$ Sentence Condition, $F(4,120)=3.54, p=.017$, interaction (see Figures 3-5).

Since the emphasis in this study was on the pattern of condition differences within each group, we followed up on this interaction by conducting within-group ANOVAs for the three conditions in each mood separately. In addition, we explored between-group differences, running repeated measures ANOVAs with sentence condition and region as within-subjects factors, and group as between-subjects factor for each mood condition separately.

Neutral mood. In schizophrenia, within-group analyses revealed more negative $\mathrm{N} 400$ amplitude for BCV relative to $\mathrm{EW}(p=.05)$, but no difference between WCV and BCV $(p>.05)$. In HC, results reported in Pinheiro, Del Re, Nestor et al. (2013) were: N400 amplitude was less negative for EW relative to both WCV and $\mathrm{BCV}$, and N400 to WCV was less negative than N400 to BCV. Between-group analysis indicated no significant main effect of group or interaction involving the between-subjects group factor $(p>.05)$.

Positive mood. In schizophrenia, within-group analyses showed that, relative to EW, N400 was more negative for $\mathrm{WCV}(p=.001)$

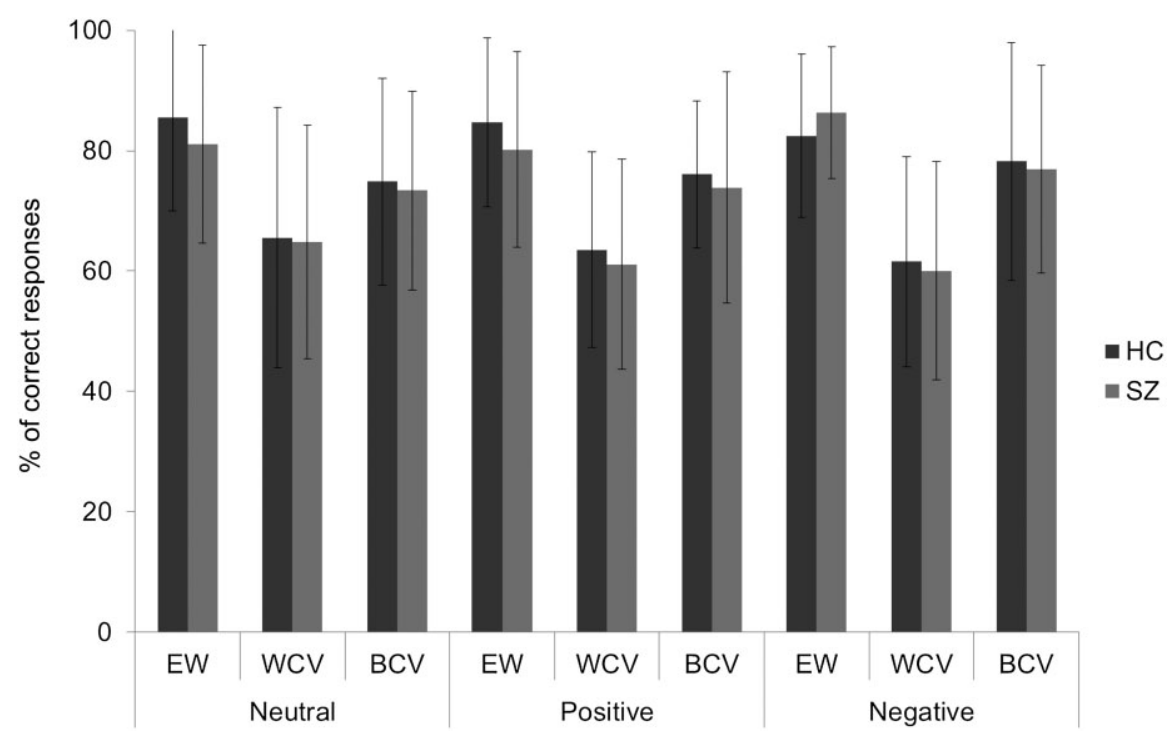

Figure 2. Percentage of correct responses in both healthy controls (HC) and schizophrenia patients (SZ). 
Neutral Mood

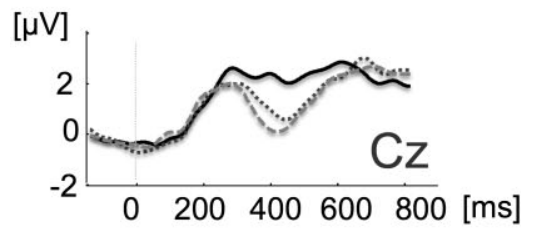

Neutral Mood

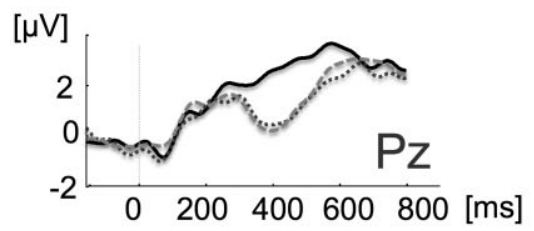

Positive Mood

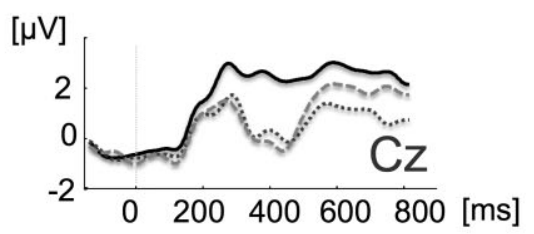

Positive Mood

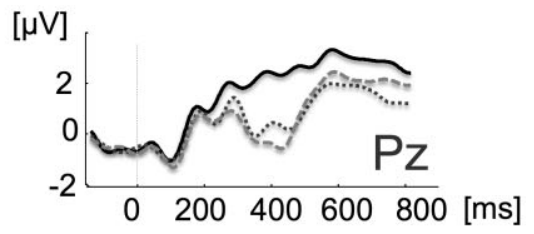

Negative Mood

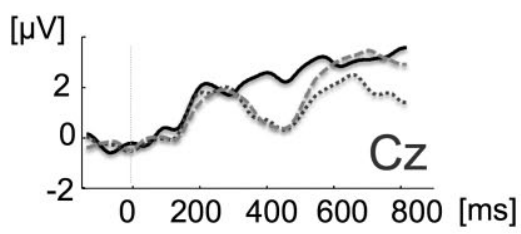

- EW -.......WCV ----BCV

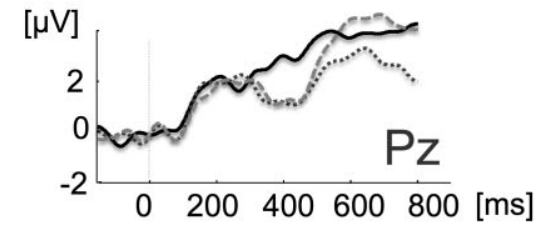

Figure 3. Grand-average waveforms for each sentence condition (EW, WCV, and BCV) in the neutral, positive, and negative moods, at $\mathrm{Cz}$, and $\mathrm{Pz}$ electrodes, in schizophrenia.

and $\operatorname{BCV}(p<.001)$. No condition difference was observed between $\mathrm{WCV}$ and $\mathrm{BCV}(p>.05)$. In $\mathrm{HC}$, results reported in Pinheiro, Del Re, Nestor et al. (2013) were: N400 was less negative for $\mathrm{EW}$ and $\mathrm{WCV}$ relative to $\mathrm{BCV}$, with no amplitude difference between EW and WCV. Between-group analysis revealed a marginally significant Group $\times$ Sentence Condition $\times$ Electrodes interaction, $F(4,120)=2.09, p=.09: \mathrm{N} 400$ tended to be more negative in the patients group than in $\mathrm{HC}$ for $\mathrm{WCV}$ at electrodes of the right hemisphere $(p=.09)$.

Negative mood. In schizophrenia, the difference between EW and $\mathrm{BCV}$ was only marginally significant; that is, N400 amplitude tended to be more negative for $\mathrm{BCV}$ relative to $\mathrm{EW}(p=.08)$; $\mathrm{N} 400$ to WCV did not differ from N400 to BCV $(p>.05)$. In HC, results reported in Pinheiro, Del Re, Nestor et al. (2013) were: N400 was more negative for $\mathrm{WCV}$ and $\mathrm{BCV}$ relative to $\mathrm{EW}$, with no amplitude difference between the two types of invalid sentence endings. In between-group analysis, a significant Group $\times$ Sentence Condition interaction was observed, $F(2,60)=3.14, p=.05$. Pairwise comparisons showed that $\mathrm{N} 400$ for $\mathrm{EW}$ was more negative in schizophrenia patients relative to HC ( $p=.03)$, but no group differences were observed for WCV $(p=.46)$ and BCV $(p=.49)$.

Considering that patients and controls differed in SES and full scale IQ (FSIQ), we ran a multivariate analysis of covariance, with SES and FSIQ as covariates to check if the effects of group membership on N400 amplitude were still significant after controlling for these variables. Results showed nonsignificant effects of FSIQ and SES $(p>.05)$.

\section{Correlations Between N400 Amplitude and Clinical and Self-Report Data in the Patients Group}

No significant associations were found $(p>.05)$.

\section{Discussion}

The research design of this study manipulated sentence context, memory structure, and mood in order to separate the effects of each of these variables on N400 amplitude in schizophrenia and control groups. The lack of group differences in the assessment of sentences as valid or invalid indicated that participants understood the sentences appropriately. The ERP results revealed a markedly different N400 pattern as a function of both sentence context and mood induction in patients when compared with $\mathrm{HC}$.

In the neutral mood condition, in HC (Pinheiro, Del Re, Nestor et al., 2013), N400 was sensitive both to contextual information and to the structure of semantic memory. In contrast, N400 in schizophrenia was sensitive only to context, as demonstrated by a congruency effect (i.e., less negative $\mathrm{N} 400$ to $\mathrm{EW}$ relative to $\mathrm{WCV}$ and $\mathrm{BCV}$ ). In the positive mood condition in $\mathrm{HC}$ (Pinheiro, Del Re, Nestor et al., 2013), mood impacted semantic processing by broadening a range of acceptable endings to include $\mathrm{WCV}$, while items that shared few semantic features with the EW were still treated as incongruent endings. In schizophrenia, the facilitative effects of positive mood on WCV processing were not observed; instead, only a congruency effect was observed. The N400 pattern to the three sentence endings in the neutral and positive mood conditions in schizophrenia was similar to the N400 results for negative mood induction in $\mathrm{HC}$, in which a similar processing of $\mathrm{WCV}$ and $\mathrm{BCV}$ (both associated with more negative N400 amplitude than EW) suggested that they were both treated as unexpected endings. In the negative mood condition in schizophrenia, despite an apparently similar N400 pattern, the difference between EW and BCV did not reach statistical significance.

Three major observations arose from within-group analysis of N400 amplitude in the schizophrenia group, corroborating our initial hypotheses. First, contrary to HC (Pinheiro, Del Re, Nestor et al., 2013), no effect of semantic memory structure (i.e., difference between WCV and BCV) was observed in schizophrenia in any of the mood conditions under study: N400 in schizophrenia patients was only sensitive to context. Second, the N400 pattern for the three sentence types in schizophrenia indicated that the effects of mood on sentence processing were not graded, contrary to the HC group where both facilitatory effects of positive mood and constraining effects of negative mood on access to semantic 
Neutral Mood
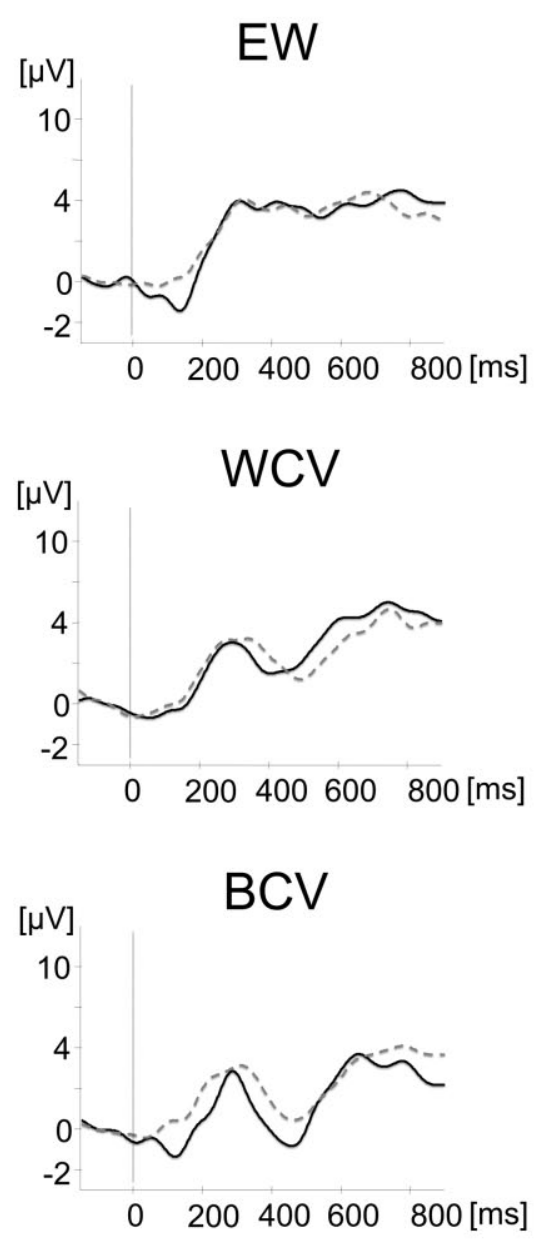

Positive Mood
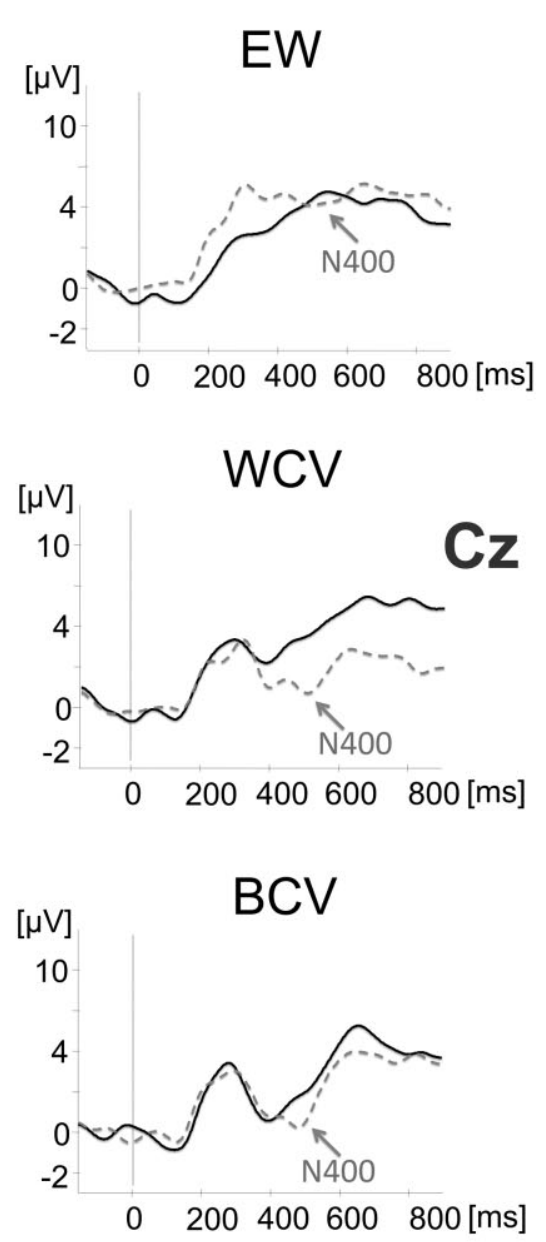

Negative Mood
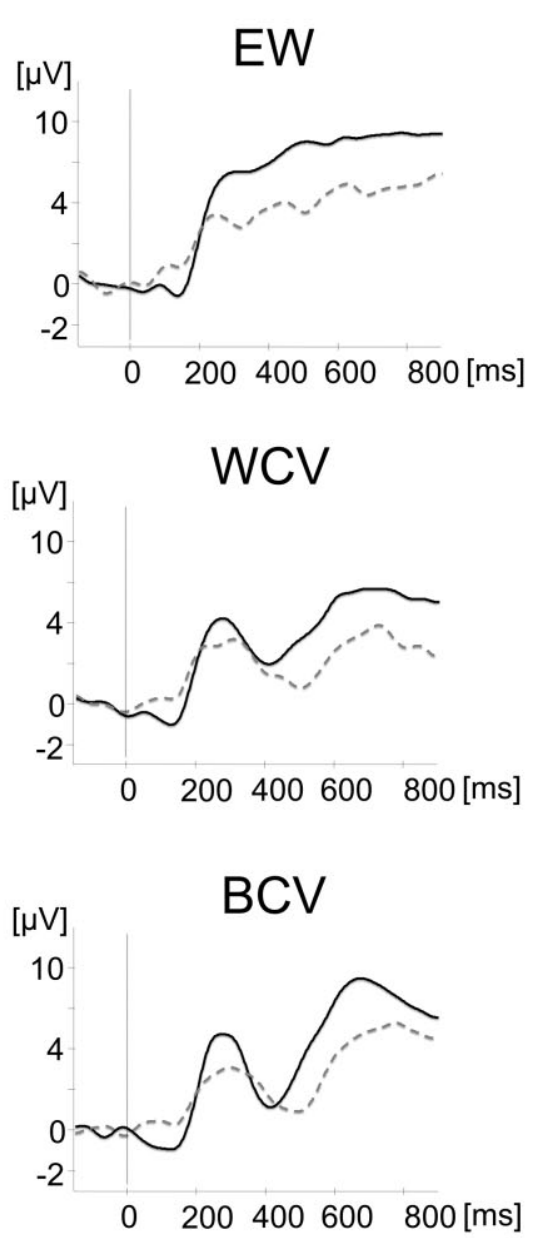

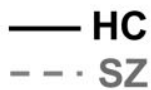

Figure 4. A: Group comparisons for each sentence condition (EW, WCV, and BCV) in neutral, positive, and negative moods, at Cz electrode. B: Group comparisons for each sentence condition (EW, WCV, and BCV) in neutral, positive, and negative moods, at Pz electrode.

information were observed. Third, results for the negative mood condition suggested that the emotional experience associated with negative pictures exacerbated N400 abnormalities in schizophrenia, by reducing the sensitivity to context. This was particularly evinced by the lack of a statistically significant difference between sentence conditions in the negative mood session, with the difference between EW and BCV being only marginally significant. Together, these findings suggest that N400 abnormalities in schizophrenia may be explained by an interaction between (a) abnormal predictive mechanisms associated with a poor use of sentence context and abnormalities in the structure and connectivity of semantic memory, and (b) increased negative emotionality.

\section{Abnormal Predictive Mechanisms in Schizophrenia}

In schizophrenia, N400 was sensitive only to context but not to the semantic feature overlap between EW and their semantic neighbors, particularly in the neutral and positive mood conditions. The clearest demonstration of these abnormal predictive mechanisms was the absence of a semantic memory effect in the neutral mood condition. Based on consistent reports of abnormal semantic memory structure and connectivity in schizophrenia (Kiang et al., 2007; Mathalon et al., 2010; Nestor et al., 1998), this finding may be explained by altered connections between words along the gradient of experientially formed category membership, which relies on the extent of semantic feature overlap (e.g., Dry \& Storms, 2010; Rosch \& Mervis, 1975). Alternatively, it may be due to abnormal semantic activation in schizophrenia: patients may activate too many words when generating context-based predictions and, consequently, go through a larger number of word candidates and/or fail to inhibit irrelevant representations (McCarley et al., 1999; Nestor et al., 2001).

\section{Effects of Negative Mood}

Patients reported more negative mood than $\mathrm{HC}$ across the three mood manipulations, corroborating previous studies (e.g., Earnst \& Kring, 1999; Pinheiro, Liu et al., 2013; Schneider, Gur, Gur, \& 

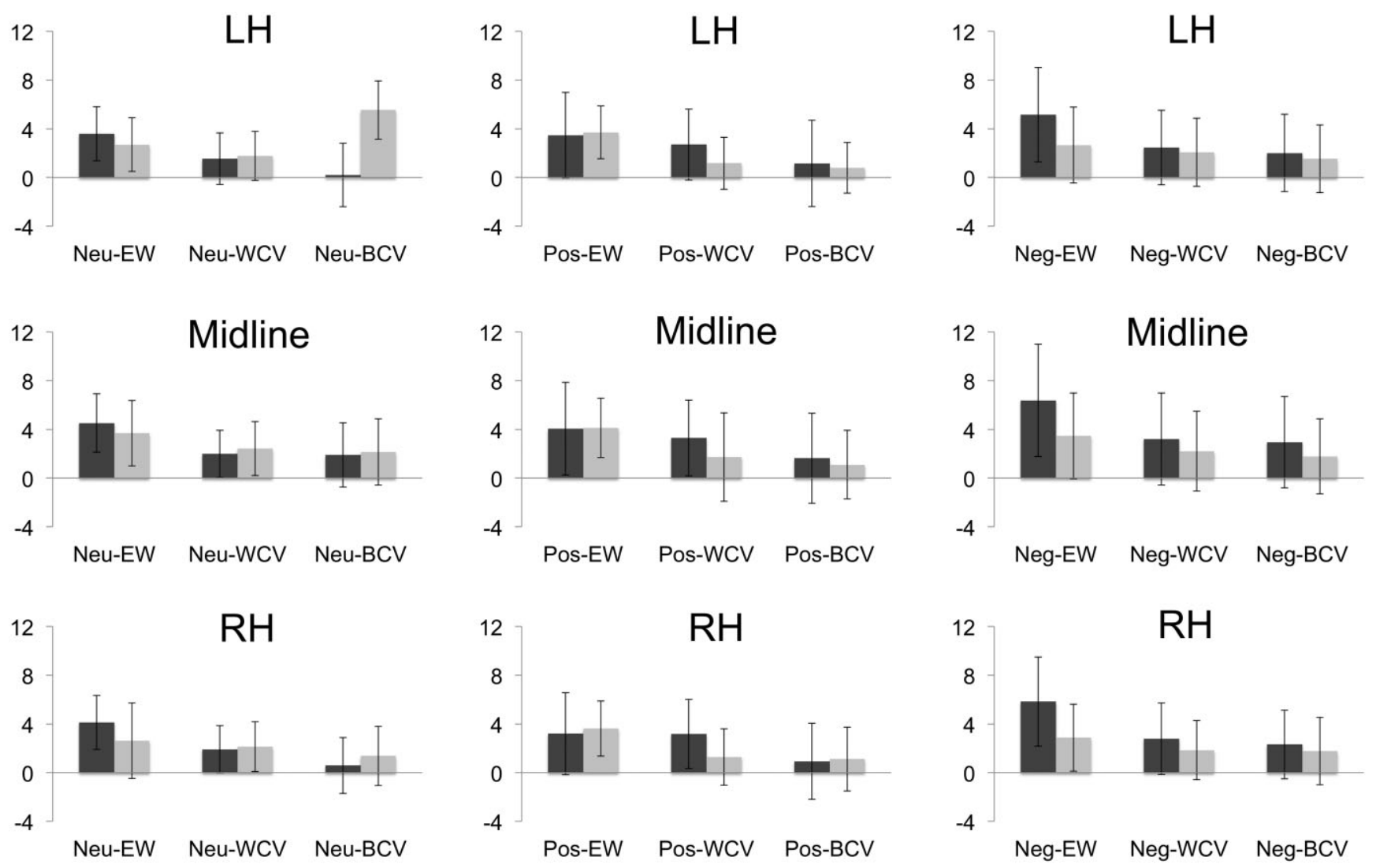

\section{HC $\square S Z$}

Figure 5. Mean N400 amplitude at left hemisphere (LH; C3/P3), midline (Cz/Pz), and right hemisphere (RH; C4/P4) electrodes, for each sentence condition in the neutral, positive, and negative moods, in healthy controls (HC) and schizophrenia patients (SZ).

Shtasel, 1995). Nonetheless, the comparison of POMS data before and after mood induction indicated that the experience of seeing evocative pictures led to specific changes in self-reported mood. Furthermore, similar ratings of valence and arousal of the three types of IAPS pictures in both groups indicated that abnormal effects of seeing evocative pictures coexisted with intact knowledge representations of visual affective stimuli in schizophrenia, consistent with our prediction and with previous studies (Pinheiro, Liu et al., 2013). While the induction of mood changes by positive and negative pictures resulted in changes in the organization of semantic memory in $\mathrm{HC}$, in schizophrenia the processing of semantic categories did not differ as a function of mood. It is plausible that the more negative mood in schizophrenia that persisted across all mood manipulations impacted sentence comprehension. It allowed the distinction between congruent and incongruent sentence endings, but not between items sharing many (WCV) or few (BCV) semantic features with a predicted word. Furthermore, group differences in the N400 pattern for neutral and positive mood conditions and in self-reported mood after neutral (e.g., reduced depression-dejection in schizophrenia) and positive mood induction suggest that the experience of neutral and positive evocative pictures did not have the same impact on sentence comprehension in $\mathrm{HC}$ and patients. In previous studies, abnormal assignment of motivational salience to neutral stimuli was proposed to account for abnormal associations in schizophrenia (Jensen et al., 2008). Abnormal mood effects related to the experi- ence of neutral pictures may also explain why we did not observe more negative N400 amplitude to incongruent sentence endings (WCV and BCV) in schizophrenia relative to $\mathrm{HC}$, as often reported in the literature (Niznikiewicz et al., 1997; Salisbury et al., 2000, 2002; Sitnikova et al., 2002). However, none of these studies used a mood induction procedure. Additionally, the N400 results for positive mood in schizophrenia suggest that evocative positive stimuli did not affect patients in the same way as HC, supporting the abnormal assignment of salience to stimuli with positive valence as reported by previous studies (Gold, Waltz, Prentice, Morris, \& Heerey, 2008; Herbener et al., 2007; Taylor, Phan, Britton, \& Liberzon, 2005).

N400 abnormalities were particularly enhanced under a negative mood in which the difference between expected and unexpected endings was only marginally significant. In addition, more negative $\mathrm{N} 400 \mathrm{EW}$ in patients relative to $\mathrm{HC}$ indicates that negative mood (in comparison with both neutral and positive moods, in which no group differences in N400 amplitude for EW were observed) decreased the ability of patients to form a prediction of a plausible final word candidate based on sentence context information. This suggests that the mood experience following the visualization of negative evocative pictures might have exacerbated sentence processing abnormalities in schizophrenia, by further impairing predictive processes and reducing the sensitivity to a sentence context (i.e., more similar processing of expected and unexpected sentences). The disruptive effects of negative mood on 
predictive processes in schizophrenia were further supported by patient reports of a stronger effect of negative pictures on their decision about the difficulty of sentences. Together, these findings indicate that the higher the intensity of a negative mood the stronger the disruptive effect on generating predictions based on semantic context and the structure of semantic memory in schizophrenia patients. An important implication of these findings is that the consistently reported semantic abnormalities in schizophrenia (e.g., Nestor et al., 1997; Niznikiewicz et al., 1997; Salisbury et al., 2000), which have been proposed as an explanation for some of the positive symptoms such as thought disorder (e.g., Spitzer, 1997), may have been driven by negative mood states, at least in chronic patients.

In spite of a different pattern of N400 effects, schizophrenia patients and HC showed similar response accuracy across moods: accuracy was higher for sentences containing EW, followed by $\mathrm{BCV}$, and then by WCV. Comparable accuracy suggests that group differences in mood effects on accessing semantic information did not prevent the patients from making semantic judgments. It further suggests that the patients compensated for abnormal sentence processing documented by ERPs at a later processing stage indexed by accuracy data (Kuperberg, Kreher, Swain, Goff, \& Holt, 2011).

\section{Limitations of Present Study}

Limitations include a relatively small sample size and the inclusion of male participants only. Even though we did not find significant associations between ERP results and medication dosage, we cannot rule out the potential effects of medication on the observed findings. Furthermore, mood effects reported in this study are restricted to affective pictures. It is possible that the use of different stimuli for mood induction purposes (e.g., sounds, words, movies) would result in different effects. Future studies should address these issues.

\section{Conclusions}

This study examined the interactions between a sentence context, semantic memory structure, and mood in schizophrenia relative to a group of HC. The N400 results suggested an abnormal structure of semantic memory in schizophrenia patients as well as faulty predictive mechanisms. Furthermore, they suggested abnormal interactions between mood and semantic memory structure. Specifically, the N400 results underscored the possible role of negative mood in exacerbating abnormalities in predictive mechanisms related to sentence context processing and access to semantic memory in schizophrenia.

\section{References}

American Psychiatric Association. (2000). Diagnostic and statistical manual of mental disorders (4th ed.). Washington, DC: American Psychiatric Association Press.

Andreasen, N. C. (1983). Scale for assessment of negative symptoms (SANS). Iowa City, IA: University of Iowa.

Andreasen, N. C. (1984). Scale for assessment of positive symptoms $(S A P S)$. Iowa City, IA: University of Iowa.

Bolte, A., Goschke, T., \& Kuhl, J. (2003). Emotion and intuition: Effects of positive and negative mood on implicit judgments of semantic coherence. Psychological Science, 14, 416-421.

Bradley, M. M., \& Lang, P. J. (1994). Measuring emotion: The SelfAssessment Manikin and the semantic differential. Journal of Behavior Therapy and Experimental Psychiatry, 25, 49-59.

Brown, G. D. A. (1984). A frequency count of 190,000 words in the London-Lund Corpus of English Conversation. Behaviour Research Methods, Instrumentation and Computers, 16, 502-532.

Canli, T., Amin, Z., Haas, B., Omura, K., \& Constable, R. T. (2004). A double dissociation between mood states and personality traits in the anterior cingulate. Behavioral Neuroscience, 118, 897-904.

Collins, A. M., \& Loftus, E. F. (1975). A spreading-activation theory of semantic processing. Psychological Review, 82, 407-428.

Coltheart, M. (1981). The MRC psycholinguistics database. Quarterly Journal of Experimental Psychology, 33A, 497-505.

Condray, R., Siegle, G. J., Cohen, J. D., van Kammen, D. P., \& Steinhauer, S. R. (2003). Automatic activation of the semantic network in schizophrenia: Evidence from event-related brain potentials. Biological Psychiatry, 54, 1134-1148.

Deacon, D., Hewitt, S., Yang, C., \& Nagata, M. (2000). Event-related potential indices of semantic priming using masked and unmasked words: Evidence that the N400 does not reflect a post-lexical process. Cognitive Brain Research, 9, 137-146.

Demirtas-Tatlidede, A., Freitas, C., Pascual-Leone, A., \& Schmahmann, J. D. (2011). Modulatory effects of theta burst stimulation on cerebellar nonsomatic functions. Cerebellum, 10, 495-503.

Docherty, N. M., \& Hebert, A. S. (1997). Comparative affective reactivity of different types of communication disturbances in schizophrenia. Journal of Abnormal Psychology, 106, 325-330.

Dreisbach, G. (2006). How positive affect modulates cognitive control: The costs and benefits of reduced maintenance capability. Brain and Cognition, 60, 11-19.

Dreisbach, G., \& Goschke, T. (2004). How positive affect modulates cognitive control: Reduced perseveration at the cost of increased distractibility. Journal of Experimental Psychology: Learning, Memory, and Cognition, 30, 343-353.

Dry, M. J., \& Storms, G. (2010). Features of graded category structure: Generalizing the family resemblance and polymorphous concept models. Acta Psychologica, 133, 244-255.

Earnst, K. S., \& Kring, A. M. (1999). Emotional responding in deficit and non-deficit schizophrenia. Psychiatry Research, 88, 191-207.

Federmeier, K. D., Kirson, D. A., Moreno, E. M., \& Kutas, M. (2001). Effects of transient, mild mood states on semantic memory organization and use: An event-related potential investigation in humans. Neuroscience Letters, 305, 149-152.

Federmeier, K. D., \& Kutas, M. (1999a). A rose by any other name: Long-term memory structure and sentence processing. Journal of Memory and Language, 41, 469-495.

Federmeier, K. D., \& Kutas, M. (1999b). Right words and left words: Electrophysiological evidence for hemispheric differences in meaning processing. Brain Research Cognitive Brain Research, 8, 373 392.

First, M. B., Spitzer, R. L., Gibbon, M., \& Williams, J. B. M. (1995). Structured Clinical Interview for DSM-IV Axis II Personality Disorders (SCID-II, version 2.0). New York, NY: Biometrics Research Department, New York State Psychiatric Institute.

First, M. B., Spitzer, R. L., Gibbon, M., \& Williams, J. B. W. (2002). Structured Clinical Interview for DSM-IV Axis I Diagnosis-Patient Edition (SCID-I/P, version 2.0). New York, NY: Biometric Research Department, New York State Psychiatric Institute.

Gold, J. M., Waltz, J. A., Prentice, K. J., Morris, S. E., \& Heerey, E. A. (2008). Reward processing in schizophrenia: A deficit in the representation of value. Schizophrenia Bulletin, 34, 835-847.

Gratton, G., Coles, M. G., \& Donchin, E. (1983). A new method for off-line removal of ocular artifact. Electroencephalography and Clinical Neurophysiology, 55, 468-484.

Gur, R. E., McGrath, C., Chan, R. M., Schroeder, L., Turner, T., Turetsky, B. I., . . Gur, R. C. (2002). An fMRI study of facial emotion processing in patients with schizophrenia. American Journal of Psychiatry, 159, 1992-1999.

Habel, U., Pauly, K., Koch, K., Kellermann, T., Reske, M., Backes, V., . . . Schneider, F. (2010). Emotion-cognition interactions in schizophrenia. World Journal of Biological Psychiatry, 11, 934-944.

Herbener, E. S., Rosen, C., Khine, T., \& Sweeney, J. A. (2007). Failure of positive but not negative emotional valence to enhance memory in schizophrenia. Journal of Abnormal Psychology, 116, 43-55. 
Herbener, E. S., Song, W., Khine, T. T., \& Sweeney, J. A. (2008). What aspects of emotional functioning are impaired in schizophrenia? Schizophrenia Research, 98, 239-246.

Holcomb, P. J. (1993). Semantic priming and stimulus degradation: Implications for the role of the $\mathrm{N} 400$ in language processing. Psychophysiology, 30, 47-61.

Horan, W. P., Wynn, J. K., Kring, A. M., Simons, R. F., \& Green, M. F. (2010). Electrophysiological correlates of emotional responding in schizophrenia. Journal of Abnormal Psychology, 119, 18-30.

Isen, A. M., Johnson, M. M. S., Mertz, E., \& Robinson, G. F. (1985). The influence of positive affect on the unusualness of word associations. Journal of Personality and Social Psychology, 48, 1413-1426.

Jensen, J., Willeit, M., Zipursky, R. B., Savina, I., Smith, A. J., Menon, M., ... Kapur, S. (2008). The formation of abnormal associations in schizophrenia: Neural and behavioral evidence. Neuropsychopharmacology, 33, 473-479.

Kay, S. R., Fiszbein, A., \& Opler, L. A. (1987). The positive and negative syndrome scale (PANSS) for schizophrenia. Schizophrenia Bulletin, 13, 261-276.

Kiang, M., Kutas, M., Light, G. A., \& Braff, D. L. (2007). Electrophysiological insights into conceptual disorganization in schizophrenia. Schizophrenia Research, 92, 225-236.

Kiefer, M., Martens, U., Weisbrod, M., Hermle, L., \& Spitzer, M. (2009). Increased unconscious semantic activation in schizophrenia patients with formal thought disorder. Schizophrenia Research, 114, 79-83.

Kring, A. M., Barrett, L. F., \& Gard, D. E. (2003). On the broad applicability of the affective circumplex: Representations of affective knowledge among schizophrenia patients. Psychological Science, 14, 207-214.

Kring, A. M., \& Neale, J. M. (1996). Do schizophrenic patients show a disjunctive relationship among expressive, experiential, and psychophysiological components of emotion? Journal of Abnormal Psychology, 105, 249-257.

Kumar, N., \& Debruille, J. B. (2004). Semantics and N400: Insights for schizophrenia. Journal of Psychiatry \& Neuroscience, 29, 89-98.

Kuperberg, G. R., Kreher, D. A., Swain, A., Goff, D. C., \& Holt, D. J. (2011). Selective emotional processing deficits to social vignettes in schizophrenia: An ERP study. Schizophrenia Bulletin, 37, 148-163.

Kutas, M., \& Federmeier, K. D. (2000). Electrophysiology reveals semantic memory use in language comprehension. Trends in Cognitive Science, 4, 463-470.

Lang, P. J., Bradley, M. M., \& Cuthbert, B. N. (2008). International affective picture system (IAPS): Affective ratings of pictures and instruction manual. Technical Report A-8. Gainesville, FL: University of Florida.

Leitman, D. I., Laukka, P., Juslin, P. N., Saccente, E., Butler, P., \& Javitt, D. C. (2010). Getting the cue: Sensory contributions to auditory emotion recognition impairments in schizophrenia. Schizophrenia Bulletin, 36, 545-556.

Mathalon, D. H., Roach, B. J., \& Ford, J. M. (2010). Automatic semantic priming abnormalities in schizophrenia. International Journal of Psychophysiology, 75, 157-166.

McCarley, R. W., Niznikiewicz, M. A., Salisbury, D. F., Nestor, P. G., O’Donnell, B. F., Hirayasu, Y., ... Shenton, M. E. (1999). Cognitive dysfunction in schizophrenia: Unifying basic research and clinical aspects [Supplement 4]. European Archives of Psychiatry and Clinical Neurosciences, 249, 69-82.

McNair, D. M., Lorr, M., \& Droppleman, L. F. (1971). Profile of mood states. San Diego, CA: Educational \& Industrial Testing Service.

Mohammad, O. M., \& DeLisi, L. E. (2013). N400 in schizophrenia patients. Current Opinion in Psychiatry, 26, 196-207.

Myin-Germeys, I., Nicolson, N. A., \& Delespaul, P. A. (2001). The context of delusional experiences in the daily life of patients with schizophrenia. Psychological Medicine, 31, 489-498.

Myin-Germeys, I., \& van Os, J. (2007). Stress-reactivity in psychosis: Evidence for an affective pathway to psychosis. Clinical Psychology Review, 27, 409-424.

Nestor, P. G., Akdag, S. J., O’Donnell, B. F., Niznikiewicz, M., Law, S., Shenton, M. E., \& McCarley, R. W. (1998). Word recall in schizophrenia: A connectionist model. American Journal of Psychiatry, 155, 1685-1690.

Nestor, P. G., Han, S. D., Niznikiewicz, M., Salisbury, D., Spencer, K., Shenton, M. E., \& McCarley, R. W. (2001). Semantic disturbance in schizophrenia and its relationship to the cognitive neuroscience of attention. Biological Psychology, 57, 23-46.

Nestor, P. G., Kimble, M. O., O’Donnell, B. F., Smith, L., Niznikiewicz, M., Shenton, M. E., \& McCarley, R. W. (1997). Aberrant semantic activation in schizophrenia: A neurophysiological study. American Journal of Psychiatry, 154, 640-646.

Niznikiewicz, M., Mittal, M. S., Nestor, P. G., \& McCarley, R. W. (2010). Abnormal inhibitory processes in semantic networks in schizophrenia. International Journal of Psychophysiology, 75, 133-140.

Niznikiewicz, M. A., O’Donnell, B. F., Nestor, P. G., Smith, L., Law, S., Karapelou, M., . . . McCarley, R. W. (1997). ERP assessment of visual and auditory language processing in schizophrenia. Journal of Abnormal Psychology, 106, 85-94.

Oldfield, R. C. (1971). The assessment and analysis of handedness: The Edinburgh inventory. Neuropsychologia, 9, 97-113.

Onitsuka, T., Oribe, N., Nakamura, I., \& Kanba, S. (2013). Review of neurophysiological findings in patients with schizophrenia. Psychiatry and Clinical Neurosciences, 67, 461-470.

Paulsen, J. S., Romero, R., Chan, A., Davis, A. V., Heaton, R. K., \& Jeste, D. V. (1996). Impairment of the semantic network in schizophrenia. Psychiatry Research, 63, 109-121.

Pauly, K., Seiferth, N. Y., Kellermann, T., Backes, V., Vloet, T. D., Shah, N. J., . . Kircher, T. T. (2008). Cerebral dysfunctions of emotioncognition interactions in adolescent-onset schizophrenia. Journal of the American Academy of Child and Adolescent Psychiatry, 47, 1299-1310.

Phillips, L. H., Bull, R., Adams, E., \& Fraser, L. (2002). Positive mood and executive functions: Evidence from Stroop and fluency tasks. Emotion, $2,12-22$.

Pinheiro, A. P., Del Re, E., Mezin, J., Nestor, P. G., Rauber, A., McCarley, R. W., ... Niznikiewicz, M. (2013). Sensory-based and higher-order operations contribute to abnormal emotional prosody processing in schizophrenia: An electrophysiological investigation. Psychological Medicine, 43, 603-618.

Pinheiro, A. P., Del Re, E., Nestor, P. G., McCarley, R. W., Goncalves, O. F., \& Niznikiewicz, M. (2013). Interactions between mood and the structure of semantic memory: Event-related potentials evidence. Social Cognitive \& Affective Neuroscience, 8, 579-594.

Pinheiro, A. P., Liu, T., Nestor, P. G., McCarley, R. W., Goncalves, O. F., \& Niznikiewicz, M. A. (2013). Visual emotional information processing in male schizophrenia patients: Combining ERP, clinical and behavioral evidence. Neuroscience Letters, 550, 75-80.

Rosch, E. (1999). Principles of categorization. In E. Margolis \& S. Laurence (Eds.), Concepts: Core readings. Boston, MA: Massachusetts Institute of Technology.

Rosch, E., \& Mervis, C. B. (1975). Family resemblances-Studies in internal structure of categories. Cognitive Psychology, 7, 573-605.

Rowe, G., Hirsh, J. B., \& Anderson, A. K. (2007). Positive affect increases the breadth of attentional selection. Proceedings of National Academy of Sciences U S A, 104, 383-388.

Salisbury, D. F., O’Donnell, B. F., McCarley, R. W., Nestor, P. G., \& Shenton, M. E. (2000). Event-related potentials elicited during a context-free homograph task in normal versus schizophrenic subjects. Psychophysiology, 37, 456-463.

Salisbury, D. F., Shenton, M. E., Nestor, P. G., \& McCarley, R. W. (2002). Semantic bias, homograph comprehension, and event-related potentials in schizophrenia. Clinical Neurophysiology, 113, 383-395.

Schneider, F., Gur, R. C., Gur, R. E., \& Shtasel, D. L. (1995). Emotional processing in schizophrenia: Neurobehavioral probes in relation to psychopathology. Schizophrenia Research, 17, 67-75.

Sitnikova, T., Salisbury, D. F., Kuperberg, G., \& Holcomb, P. I. (2002). Electrophysiological insights into language processing in schizophrenia. Psychophysiology, 39, 851-860.

Spitzer, M. (1997). A cognitive neuroscience view of schizophrenic thought disorder. Schizophrenia Bulletin, 23, 29-50.

Storms, L. H., Clopton, J. M., \& Wright, C. (1982). Effects of gluten on schizophrenics. Archives of General Psychiatry, 39, 323-327.

Taylor, S. F., Phan, K. L., Britton, J. C., \& Liberzon, I. (2005). Neural response to emotional salience in schizophrenia. Neuropsychopharmacology, 30, 984-995.

Wechsler, D. (1997). Wechsler Adult Intelligence Scale: Administration and scoring manual (3rd ed. San Antonio, TX: The Psychological Corporation.

Wilson, M. D. (1998). The MRC psycholinguistic database: Machine readable dictionary (v. 2). Behavior Research Methods, Instruments, \& Computers, 20, 6-11.

Wulff, K., Dijk, D., Foster, R. G., \& Joyce, E. M. (2012). Sleep and circadian rhythm disruption in schizophrenia. British Journal of Psychiatry, 200, 308-316.

(Received March 4, 2014; ACCEPTED June 8, 2014) 